Supporting Information

\title{
Fast wetting of fullerene capping layer improves the efficiency and scalability of perovskite solar cells
}

Bairu Li, ${ }^{\dagger}$ Xin Yu, ${ }^{\dagger}$ Lingbo Jia, ${ }^{\dagger}$ Mengmeng Zhang, ${ }^{\dagger}$ Wanpei Hu, ${ }^{\dagger}$ Yanbo Shang, ${ }^{\dagger}$ Xingcheng Li, ${ }^{\dagger}$ Liming Ding, ${ }^{\dot{+}}$ Jixian $X u,{ }^{*} \dot{\dagger}$ and Shangfeng Yang ${ }^{*} \dot{\dagger}$

${ }^{\dagger}$ Hefei National Laboratory for Physical Sciences at Microscale, CAS Key Laboratory of Materials for Energy Conversion, Anhui Laboratory of Advanced Photon Science and Technology, Department of Materials Science and Engineering, University of Science and Technology of China, Hefei 230026, China

$\$$ Center for Excellence in Nanoscience (CAS), Key Laboratory of Nanosystem and Hierarchical Fabrication (CAS), National Center for Nanoscience and Technology, Beijing 100190, China

* Corresponding Authors. E-mail: jixianxu@ustc.edu.cn; sfyang@ustc.edu.cn 


\section{Contents}

S1. Changes of contact angles of different solvents over time.

S2. Surface tensions and viscosities of different IPA:CB hybrid solvents.

S3. Cross-sectional SEM images of perovskite films covered with different PCBM capping layers.

S4. UV-vis absorption spectra of PCBM films.

S5. Electron mobilities of PSC devices with different PCBM capping layers.

S6. Analysis of time-resolved photoluminescence (TRPL) spectra of the perovskite films covered with different PCBM capping layers.

S7. Statistic photovoltaic parameters of PSC devices based on different PCBM ETLs.

S8. Photovoltaic parameters of PSC devices in different scan directions.

S9. Stabilized photocurrent densities and power outputs of PSC devices.

S10. EQE spectra of PSC devices measured in the ambient condition.

S11. Photovoltaic parameters of large-area $\left(1 \mathrm{~cm}^{2}\right)$ devices.

S12. Device parameters vary with a function of storage time.

S13. Photovoltaic parameters of PSC devices with PCBM ETLs prepared from other alcohols blended with CB.

S14. Photovoltaic parameters of PSC devices based on C60-3-Py ETL.

S15. Stabilized photocurrent density and power output of the champion PSC devices fabricated though a drop-casting method.

S16. SEM images of perovskite films treated without and with 0.15IPA:CB hybrid solvent. 
S1. Changes of contact angles of different solvents over time.
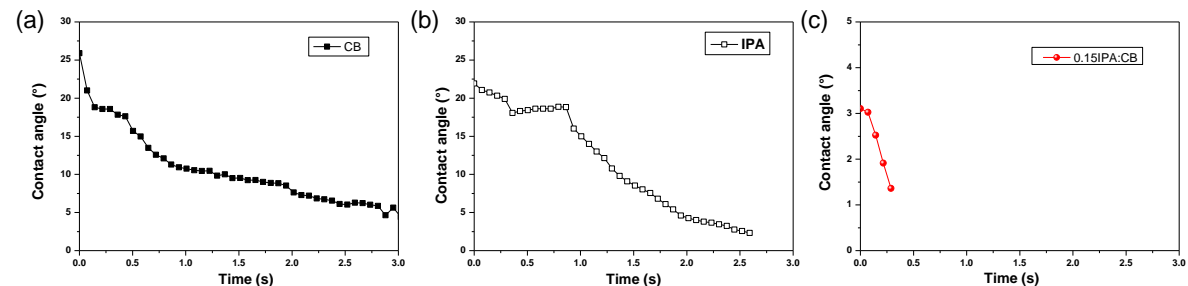

Figure S1. Changes of contact angles of (a) pure CB, (b) pure IPA and (c) 0.15IPA:CB hybrid solvent dropped onto $\mathrm{CH}_{3} \mathrm{NH}_{3} \mathrm{PbI}_{3}$ perovskite films over time.

\section{S2. Surface tensions and viscosites of different IPA:CB hybrid solvents.}

Table S1. Surface tensions and viscosities of different solvents.

\begin{tabular}{|c|c|c|c|c|c|c|c|}
\hline $\begin{array}{l}\text { Volume } \\
\text { ratio of } \\
\text { IPA:CB }\end{array}$ & $\begin{array}{c}\text { Volume } \\
\text { percentage } \\
\text { of IPA }{ }^{[a]}\end{array}$ & $\begin{array}{c}\text { Surface } \\
\text { tension } \\
\left(\gamma_{\mathrm{x}},\right. \\
\mathrm{mN} / \mathrm{m})\end{array}$ & $\begin{array}{c}\text { Viscosity } \\
\quad\left(\boldsymbol{\eta}_{x},\right. \\
\text { mPa.S })\end{array}$ & $\begin{array}{c}\text { Calculated } \\
\text { surface } \\
\text { tension } \\
\gamma_{\text {IPA:CB }}[\mathbf{b}] \\
(\mathbf{m N} / \mathbf{m}) \\
\end{array}$ & $\begin{array}{c}\text { Calculated } \\
\text { viscosity } \\
\eta_{\text {IPA:CB }} \\
(\mathbf{m P a} \cdot \mathbf{S})\end{array}$ & $\begin{array}{c}\left(\gamma_{\mathrm{CB}}-\gamma_{\mathrm{x}}\right) / \\
\left(\gamma_{\mathrm{CB}}-\gamma_{\mathrm{IPA}}\right)\end{array}$ & $\begin{array}{c}\left(\boldsymbol{\eta}_{\mathrm{CB}}-\boldsymbol{\eta}_{\mathrm{x}}\right) / \\
\left(\boldsymbol{\eta}_{\mathrm{CB}}-\boldsymbol{\eta}_{\mathrm{IPA}}\right)\end{array}$ \\
\hline$\overline{\mathbf{0}}$ & $0.00 \%$ & 33.75 & 0.81 & 33.75 & 0.81 & $0.00 \%$ & $0.00 \%$ \\
\hline 0.05 & $4.76 \%$ & 32.29 & 0.80 & 33.14 & 0.92 & $11.45 \%$ & $-0.64 \%$ \\
\hline 0.10 & $9.09 \%$ & 30.91 & 0.80 & 32.59 & 1.02 & $22.27 \%$ & $-0.46 \%$ \\
\hline 0.15 & $13.04 \%$ & 29.68 & 0.81 & 32.09 & 1.10 & $31.92 \%$ & $-0.02 \%$ \\
\hline 0.2 & $16.67 \%$ & 28.84 & 0.81 & 31.62 & 1.18 & $38.51 \%$ & $0.34 \%$ \\
\hline 0.25 & $20.00 \%$ & 28.01 & 0.83 & 31.20 & 1.25 & $45.02 \%$ & $1.50 \%$ \\
\hline 0.30 & $23.08 \%$ & 27.55 & 0.84 & 30.81 & 1.31 & $48.63 \%$ & $1.75 \%$ \\
\hline 0.67 & $40.00 \%$ & 25.76 & 0.96 & 28.65 & 1.63 & $62.67 \%$ & $9.40 \%$ \\
\hline 1.50 & $60.00 \%$ & 24.15 & 1.19 & 26.10 & 1.95 & $75.29 \%$ & $24.27 \%$ \\
\hline 4.00 & $80.00 \%$ & 22.55 & 1.64 & 23.55 & 2.20 & $87.84 \%$ & $52.31 \%$ \\
\hline$\infty$ & $100.00 \%$ & 21.00 & 2.40 & 21.00 & 2.40 & $100.00 \%$ & $100.00 \%$ \\
\hline
\end{tabular}

[a] The volume percentage of IPA $=\mathrm{V}_{\text {IPA }} /\left(\mathrm{V}_{\text {IPA }}+\mathrm{V}_{\mathrm{CB}}\right) \times 100 \%$, where $\mathrm{V}_{\text {IPA }}$ and $\mathrm{V}_{\mathrm{CB}}$ are the volume of IPA and $\mathrm{CB}$ in the hybrid solutions.

${ }^{[b]} \gamma_{\text {IPA:CB }}=\gamma_{\mathrm{CB}} \times \mathrm{V}_{\mathrm{CB}} /\left(\mathrm{V}_{\mathrm{CB}}+\mathrm{V}_{\mathrm{IPA}}\right)+\gamma_{\mathrm{IPA}} \times \mathrm{V}_{\mathrm{IPA}} /\left(\mathrm{V}_{\mathrm{CB}}+\mathrm{V}_{\mathrm{IPA}}\right)$.

${ }^{[c]} \eta_{\text {IPA:CB }}=\eta_{\mathrm{CB}} \times \mathrm{V}_{\mathrm{CB}} /\left(\mathrm{V}_{\mathrm{CB}}+\mathrm{V}_{\mathrm{IPA}}\right)+\eta_{\mathrm{IPA}} \times \mathrm{V}_{\mathrm{IPA}} /\left(\mathrm{V}_{\mathrm{CB}}+\mathrm{V}_{\mathrm{IPA}}\right)$.

The surface tension $\left(\gamma_{\mathrm{x}}\right)$ was measured using Attension Force Sigma 702 Tensiometer and given by the measurement system. The viscosity $\left(\eta_{\mathrm{x}}\right)$ was measured using Ubbelohde Viscometer with a diameter of $0.55 \mathrm{~mm}$ in a thermostat water bath, in which the temperature was controlled at $20{ }^{\circ} \mathrm{C} \pm 0.3{ }^{\circ} \mathrm{C}$. The viscosity of the solvent was calculated according to the Poiseuille's Law, $\eta_{\mathrm{x}}=\rho(\mathrm{kt}-\mathrm{c} / \mathrm{t})$, where $\mathrm{k}$ and $\mathrm{c}$ are the viscometer constant, $\mathrm{t}$ is the efflux time and $\rho$ is the density of the solvent. ${ }^{1}$ The density of the solvent was obtained by weighing a 1 $\mathrm{ml}$ solvent. The efflux time was measured using an electronic digital stopwatch, and the value was averaged from three repetitions within an error of $0.3 \mathrm{~s}$. 

layers.

(a)

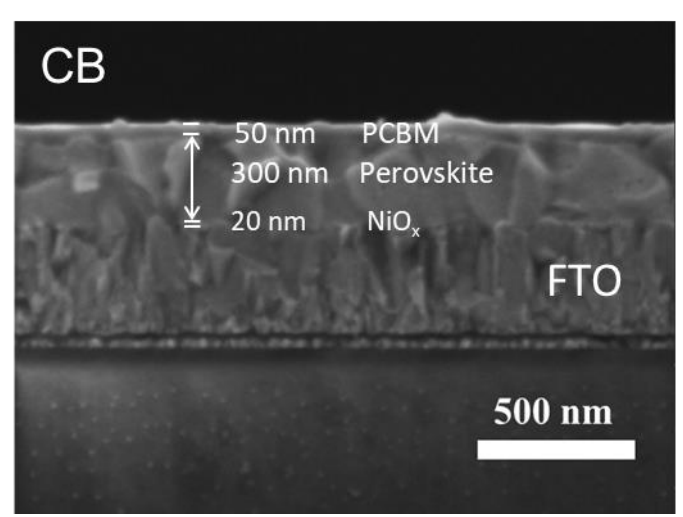

(b)

\section{$0.15 I P A: C B$}

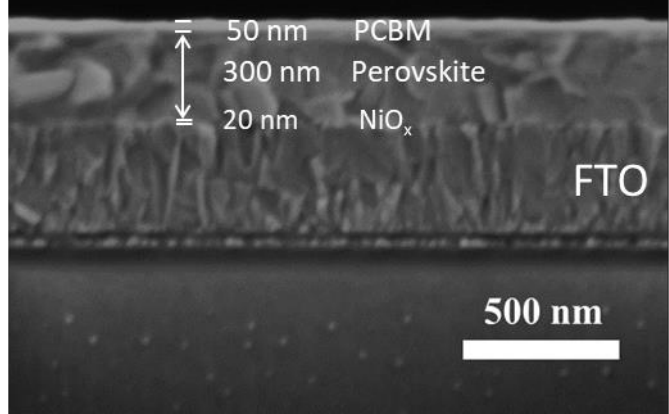

Figure S2. Cross-sectional SEM images of perovskite films covered with PCBM capping layers prepared with (a) pure CB and (b) 0.15IPA:CB hybrid solvent.

S4. UV-vis absorption spectra of PCBM films.

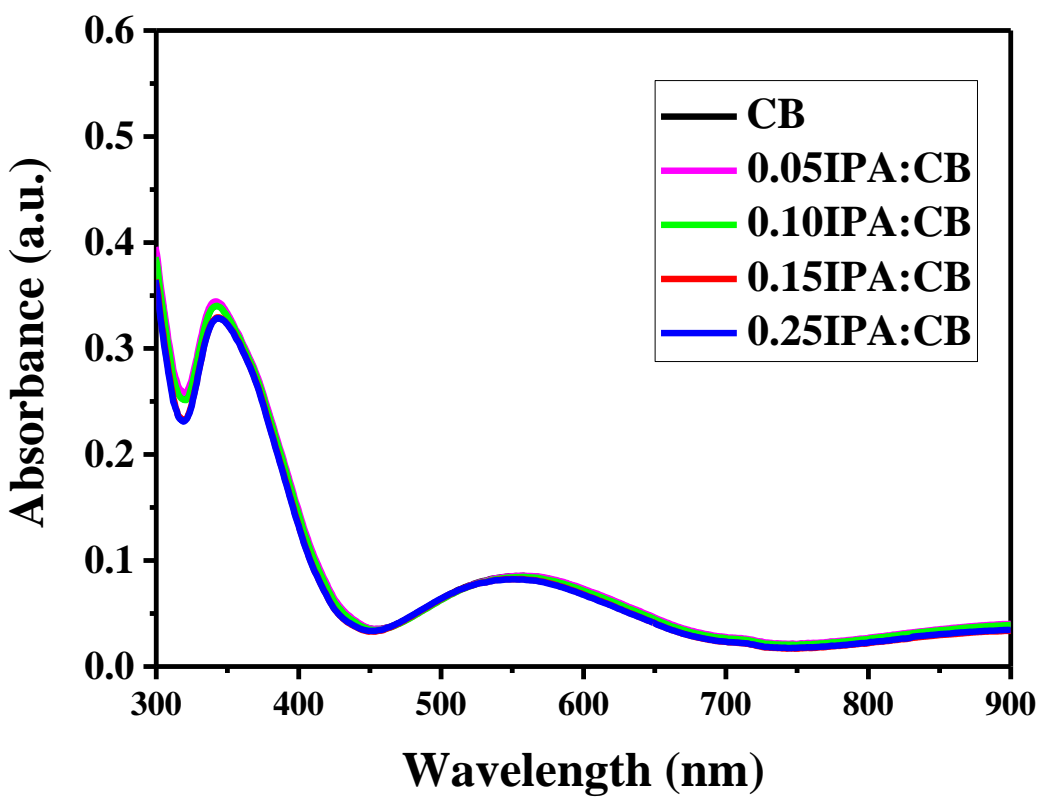

Figure S3. UV-vis absorption spectra of PCBM films spin-coated from different solvents onto glass/ITO substrate. 


\section{S5. Electron mobilities of PSC devices with different PCBM capping layers.}

The electron mobilities $\left(\mu_{\mathrm{e}}\right)$ of PSC devices with different PCBM capping layers are estimated by SCLC method based on the Mott-Gurney equation: ${ }^{2-4}$

$J_{d}=\frac{9 \varepsilon \varepsilon_{0}}{8 L^{3}} \cdot V^{2} \cdot \mu$

Where $\mathrm{J}_{\mathrm{d}}$ is current density and $\mu_{\mathrm{e}}$ is electron mobility, $\mathrm{L}$ is the thickness of the $\mathrm{CH}_{3} \mathrm{NH}_{3} \mathrm{PbI}_{3}$ film (300 nm). According to equation (S1), the estimated $\mu_{\mathrm{e}}$ of devices with different PCBM capping layers prepared from pure $\mathrm{CB}, 0.05 \mathrm{IPA}: \mathrm{CB}, 0.15 \mathrm{IPA}: \mathrm{CB}$ and $0.25 \mathrm{IPA}: \mathrm{CB}$ are $6.96 \times$ $10^{-4} \mathrm{~cm}^{2} \mathrm{~V}^{-1} \mathrm{~S}^{-1}, 8.53 \times 10^{-4} \mathrm{~cm}^{2} \mathrm{~V}^{-1} \mathrm{~S}^{-1}, 1.66 \times 10^{-3} \mathrm{~cm}^{2} \mathrm{~V}^{-1} \mathrm{~S}^{-1}$ and $1.09 \times 10^{-3} \mathrm{~cm}^{2} \mathrm{~V}^{-1} \mathrm{~S}^{-1}$, respectively.

\section{S6. Analysis of time-resolved photoluminescence (TRPL) spectra of the perovskite films covered with different PCBM capping layers.}

The time-resolved photoluminescence (TRPL) spectra of $\mathrm{CH}_{3} \mathrm{NH}_{3} \mathrm{PbI}_{3}$ perovskite film covered with different PCBM capping layers are measured to gain further understanding of the charge recombination dynamics (Figure 3d). The excitation source was a $543 \mathrm{~nm}$ picosecond laser pulse which was filtered from a supercontinuum generation. The lifetime was obtained by fitting the TRPL spectrum with a bi-exponential decay function as shown in equation $\mathrm{S} 2: 5,6$

$F(\mathrm{t})=\mathrm{A}_{1} \exp \left(-\mathrm{t} / \tau_{1}\right)+\mathrm{A}_{2} \exp \left(-\mathrm{t}-\mathrm{t} / \tau_{2}\right)+\mathrm{y}_{0}$

Where $A_{1}$ and $A_{2}$ are the decay amplitude, the decay lifetime $\tau_{1}$ and $\tau_{2}$ are the fast and slow decay time, respectively. The fast decay is usually considered to be the result of the quenching of free charges in perovskite film through transport to the electron or hole transport layers, while the slow decay is to be the result of radiative decay within perovskite layer. We calculated the average decay time $\left(\tau_{\mathrm{ave}}\right)$ according to the formula $\tau_{\mathrm{ave}}=\left(\mathrm{A}_{1} \tau_{1}{ }^{2}+\mathrm{A}_{2} \tau_{2}{ }^{2}\right) /\left(\mathrm{A}_{1} \tau_{1}+\right.$ $\mathrm{A}_{2} \tau_{2}$ ). The pristine $\mathrm{CH}_{3} \mathrm{NH}_{3} \mathrm{PbI}_{3}$ perovskite film shows a $\tau_{\text {ave }}$ of $49.06 \mathrm{~ns}$. $\mathrm{CH}_{3} \mathrm{NH}_{3} \mathrm{PbI}_{3}$ perovskite film deposited with PCBM capping layers from CB, 0.05IPA:CB, 0.15IPA:CB and 0.25IPA:CB show average lifetime of $9.78 \mathrm{~ns}, 8.57 \mathrm{~ns}, 5.73 \mathrm{~ns}$ and $6.51 \mathrm{~ns}$, respectively, indicating that electron transport from the perovskite film to PCBM-0.15IPA:CB film is the most efficient. 
Table S2. Time constants in TRPL determined by bi-exponential fittings measured on $\mathrm{CH}_{3} \mathrm{NH}_{3} \mathrm{PbI}_{3}$ perovskite films without and with different PCBM capping layers.

\begin{tabular}{llllll}
\hline Sample & $\mathbf{A 1}$ & $\mathbf{t}_{1}(\mathbf{n s})$ & $\mathbf{A}_{2}$ & $\mathbf{t}_{2}(\mathbf{n s})$ & $\mathbf{t}(\mathbf{n s})$ \\
\hline Perovskite & 0.30 & 9.67 & 0.68 & 52.25 & 49.06 \\
\hline Perovskite/PCBM(control) & 0.61 & 3.83 & 0.41 & 12.51 & 9.78 \\
\hline Perovskite/PCBM-0.05IPA:CB & 0.63 & 3.50 & 0.38 & 11.16 & 8.57 \\
\hline Perovskite/PCBM-0.15IPA:CB & 0.84 & 3.24 & 0.22 & 9.11 & 5.73 \\
\hline Perovskite/PCBM-0.25IPA:CB & 0.71 & 3.21 & 0.32 & 9.10 & 6.51 \\
\hline
\end{tabular}

S7. Statistic photovoltaic parameters of PSC devices based on different PCBM ETLs.

(a)

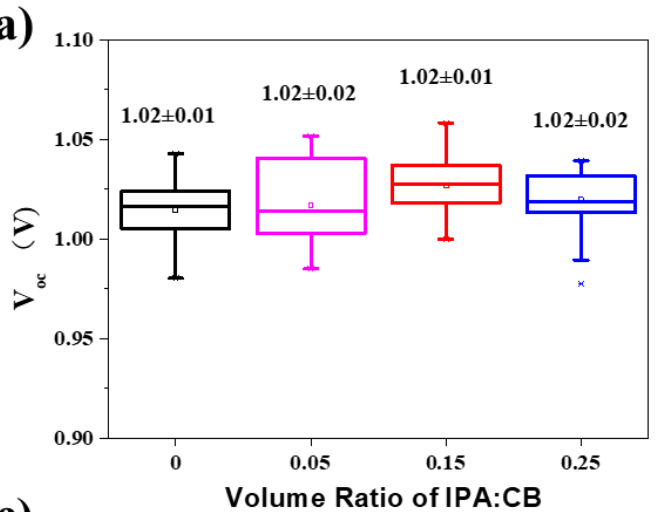

(c)

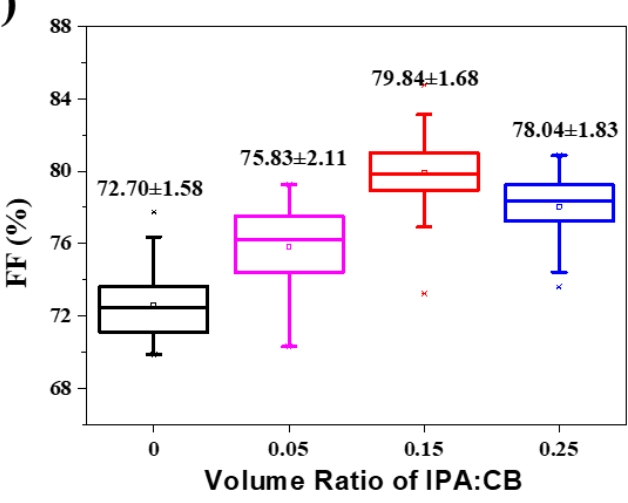

(b)

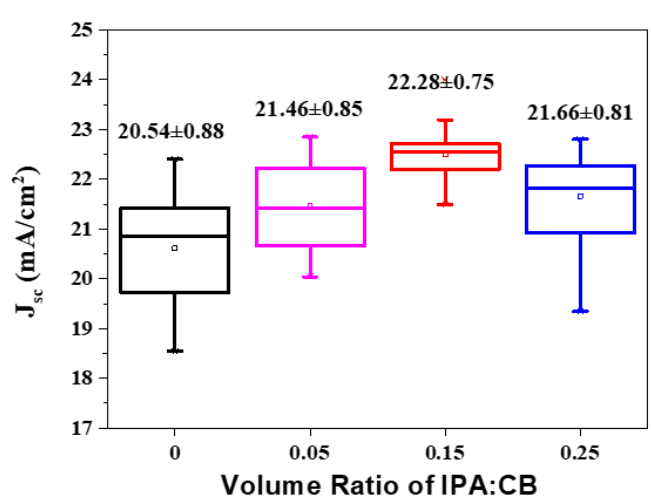

(d)

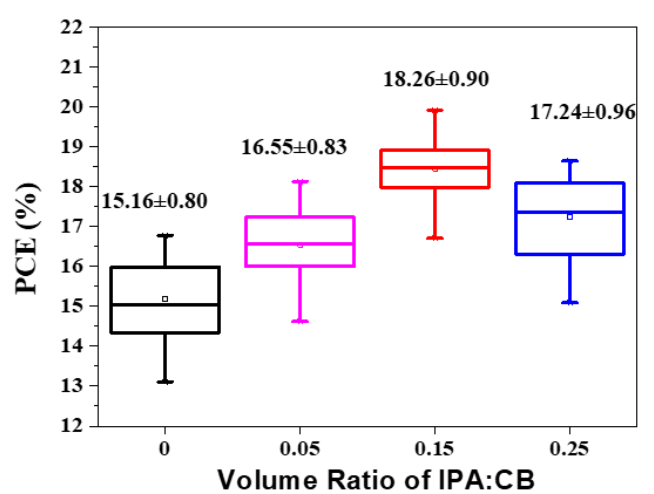

Figure S4. Box plots of (a) PCE, (b) $\mathrm{V}_{\mathrm{oc}}$, (c) $\mathrm{J}_{\mathrm{sc}}$ and (d) FF for the devices based on PCBM ETLs prepared from different volume ratios of IPA:CB. 
S8. Photovoltaic parameters of the PSC devices in different scan directions.

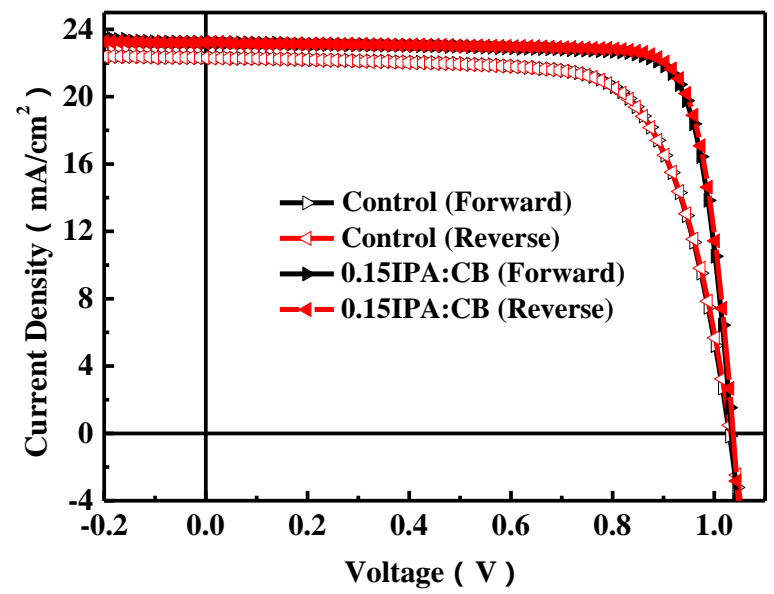

Figure S5. J-V curves of the control and PCBM-0.15IPA:CB devices under reverse and forward scans.

Table S3. Photovoltaic parameters control device and PCBM-0.15IPA:CB device different scan directions.

\begin{tabular}{cccccccc}
\hline \multirow{2}{*}{ Device } & Direction & $\mathbf{V}_{\text {oc }}(\mathbf{V})$ & $\begin{array}{c}\mathbf{J}_{\mathbf{s c}} \\
\left(\mathbf{m A} / \mathbf{c m}^{2}\right)\end{array}$ & $\mathbf{F F}(\%)$ & $\mathbf{P C E}(\%)$ & $\mathbf{R}_{\mathbf{s}}\left(\mathbf{\Omega} \cdot \mathbf{c m}^{2}\right)$ & $\mathbf{R}_{\mathbf{s h}}\left(\mathbf{\Omega} \cdot \mathbf{c m}^{2}\right)$ \\
\hline \multirow{2}{*}{ Control } & Forward & 1.03 & 22.3 & 71.85 & 16.50 & 5.0 & 1854.7 \\
& Reverse & 1.03 & 22.31 & 72.26 & 16.59 & 4.8 & 1919.2 \\
\hline \multirow{2}{*}{ 0.15IPA:CB } & Forward & 1.03 & 23.24 & 82.69 & 19.81 & 2.5 & 2915.6 \\
& Reverse & 1.04 & 23.19 & 82.81 & 19.92 & 2.6 & 3207.8 \\
\hline
\end{tabular}

S9. Stabilized photocurrent densities and power outputs of PSC devices.

(a)

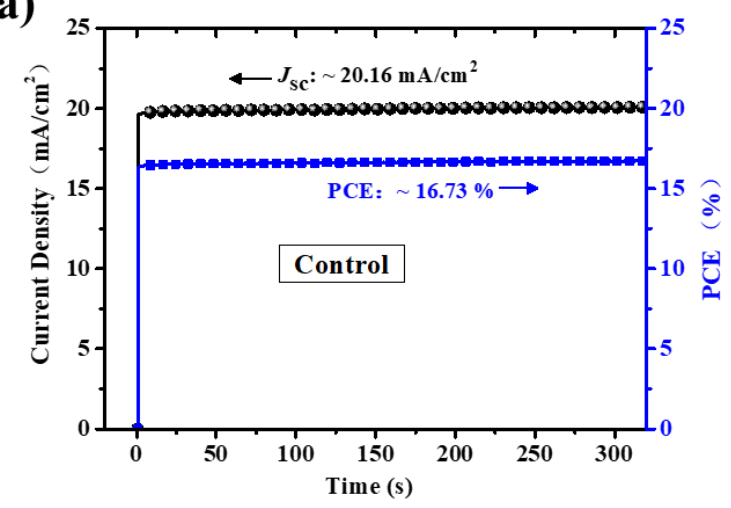

(b)

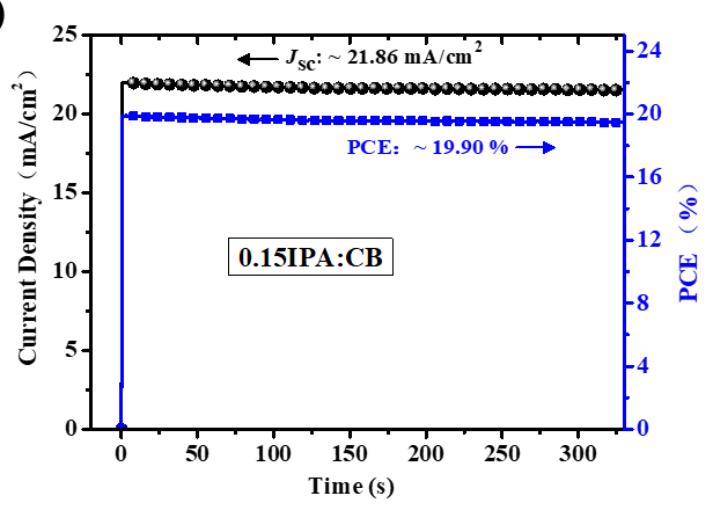

Figure S6. Stabilized photocurrent densities and power outputs measured at the maximum power points of the control and PCBM-0.15IPA:CB devices. 
S10. EQE spectra of PSC devices measured in the ambient condition.

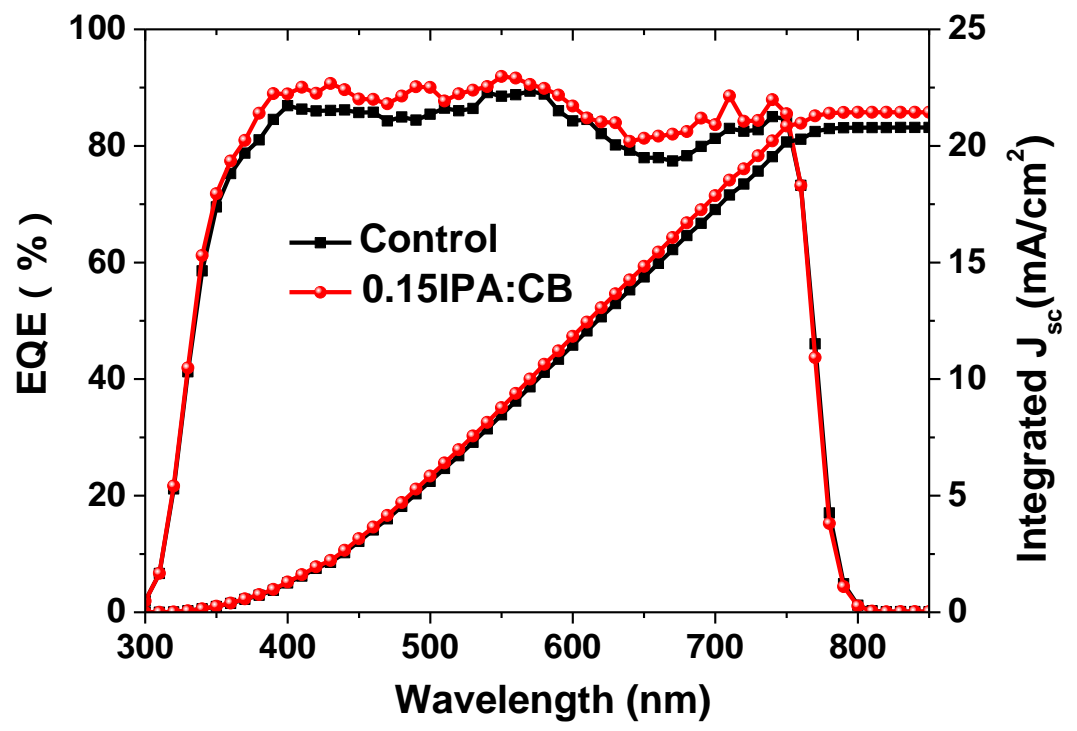

Figure S7. EQE spectra of the control and PCBM-0.15IPA:CB devices measured in the ambient condition.

S11. Photovoltaic parameters of large-area $\left(1 \mathrm{~cm}^{2}\right)$ devices.

Table S4. Photovoltaic parameters of large-area $\left(1 \mathrm{~cm}^{2}\right)$ devices with different PCBM ETLs.

\begin{tabular}{lcccccc}
\hline Device & $\mathbf{V}_{\text {oc }}(\mathbf{V})$ & $\mathbf{J}_{\text {sc }}\left(\mathbf{m A} / \mathbf{c m}^{2}\right)$ & $\mathbf{F F}(\%)$ & $\mathbf{P C E}(\%)$ & $\mathbf{R}_{\mathbf{s}}\left(\boldsymbol{\Omega} \cdot \mathbf{c m}^{2}\right)$ & $\mathbf{R}_{\mathbf{s h}}\left(\mathbf{\Omega} \cdot \mathbf{c m}^{2}\right)$ \\
\hline Control & 1.07 & 20.29 & 70.86 & 15.35 & 8.1 & 1038.7 \\
0.15IPA:CB & 1.04 & 22.09 & 75.33 & 17.38 & 7.5 & 1761.1 \\
\hline
\end{tabular}

S12. Device parameters vary with a function of storage time.
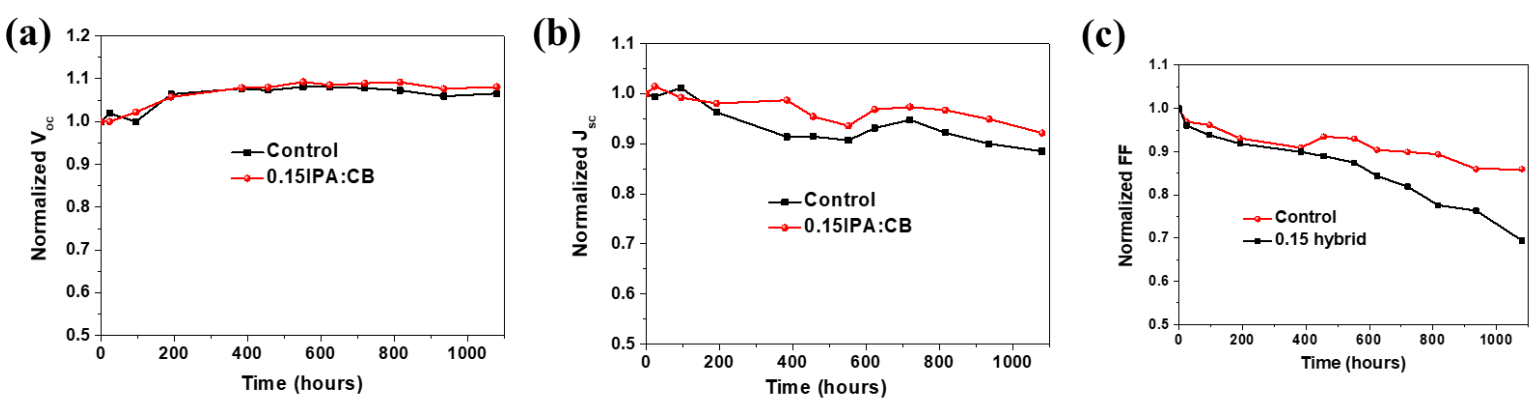

Figure S8. Variations of device parameters (a) $\mathrm{V}_{\mathrm{oc}}$, (b) $\mathrm{J}_{\mathrm{sc}}$, and (c) FF with a function of storage time. Devices were stored in a drying cabinet with a relative humidity of $35 \%$ and their performances were test in the atmosphere. 


\section{S13. Photovoltaic parameters of PSC devices with PCBM ETLs prepared from other}

alcohols blended with $\mathrm{CB}$.

Table S5. Photovoltaic parameters of perovskite solar cells with different PCBM ETLs spincoated from other alcohol (methanol and ethanol) and CB hybrid solvents.

\begin{tabular}{|c|c|c|c|c|c|c|c|}
\hline \multirow{2}{*}{ devices } & \multirow{2}{*}{$V_{o c}(\mathbf{V})$} & \multirow{2}{*}{$\begin{array}{l}J_{s c} \\
\left(\mathbf{m A} / \mathbf{c m}^{2}\right)\end{array}$} & \multirow{2}{*}{ FF $(\%)$} & \multicolumn{2}{|l|}{$\overline{P C E}(\%)$} & \multirow{2}{*}{$\begin{array}{l}R_{s}{ }^{b} \\
\left(\Omega \cdot \mathrm{cm}^{2}\right)\end{array}$} & \multirow{2}{*}{$\begin{array}{l}R_{s h}{ }^{b} \\
\left(\Omega \cdot \mathbf{c m}^{2}\right.\end{array}$} \\
\hline & & & & Average $^{a}$ & Best & & \\
\hline Control & $1.01 \pm 0.01$ & $21.28 \pm 1.38$ & $72.49 \pm 0.69$ & $15.50 \pm 1.02$ & 16.80 & 5.0 & 1909.0 \\
\hline 0.15methanol:CB & $1.03 \pm 0.01$ & $21.66 \pm 1.09$ & $76.77 \pm 1.72$ & $17.07 \pm 1.04$ & 18.15 & 4.3 & 2020.3 \\
\hline 0.15ethanol:CB & $1.04 \pm 0.01$ & $22.15 \pm 1.00$ & $79.01 \pm 1.45$ & $18.18 \pm 0.96$ & 19.66 & 4.2 & 3931.4 \\
\hline
\end{tabular}

Averaged over 8 devices fabricated independently.

${ }^{\mathrm{b}} \mathrm{R}_{\mathrm{s}}$ and $\mathrm{R}_{\mathrm{sh}}$ are obtained by the PCE measurement system.

S14. Photovoltaic parameters of PSC device based on C60-3-Py ETL.

Table S6. Photovoltaic parameters of devices based on $\mathrm{C}_{60}-3$-Py ETL prepared from pure CB (control) and 0.15IPA:CB.

\begin{tabular}{ccccccc}
\hline Device & $\begin{array}{c}\mathbf{V}_{\text {oc }} \\
(\mathbf{V})\end{array}$ & $\mathbf{J}_{\text {sc }}\left(\mathbf{m A} / \mathbf{c m}^{2}\right)$ & FF $(\%)$ & PCE $(\%)$ & $\begin{array}{c}\mathbf{R}_{\mathrm{s}} \\
\left(\boldsymbol{\Omega} \cdot \mathbf{c m}^{2}\right)\end{array}$ & $\begin{array}{c}\mathbf{R}_{\text {sh }} \\
\left(\boldsymbol{\Omega} \cdot \mathbf{c m}^{2}\right)\end{array}$ \\
\hline $\mathbf{C}_{\mathbf{6 0}}$-3-BPy (Control) & 1.05 & 22.42 & 73.88 & 17.33 & 5.3 & 2929.7 \\
$\mathbf{C}_{\mathbf{6 0}} \mathbf{- 3 - B P y - 0 . 1 5 I P A : C B}$ & 1.06 & 23.63 & 79.21 & 19.93 & 3.4 & 3658.4 \\
\hline
\end{tabular}

\section{S15. Stabilized photocurrent density and power output of the champion PSC device}

fabricated though a drop-casting method

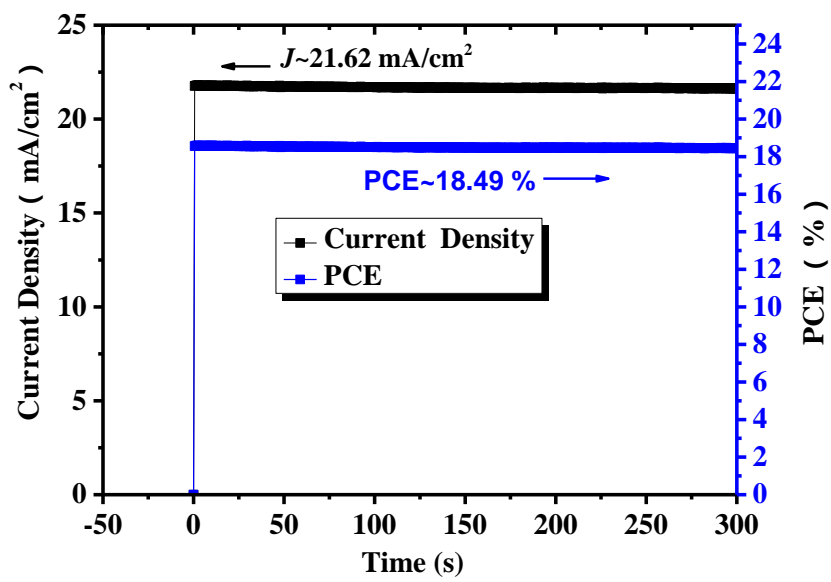

Figure S9. Stabilized photocurrent densities and power outputs measured at the maximum power points of the champion devices though a drop-casting method. 
(a)

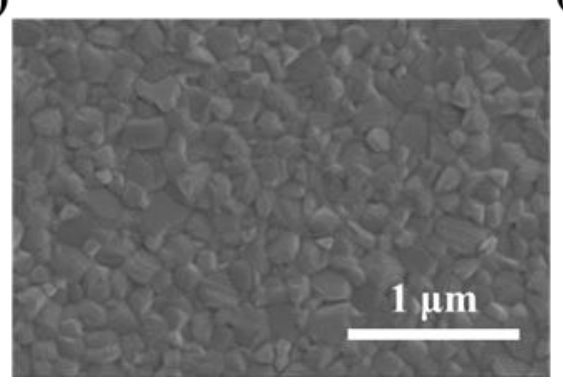

(b)

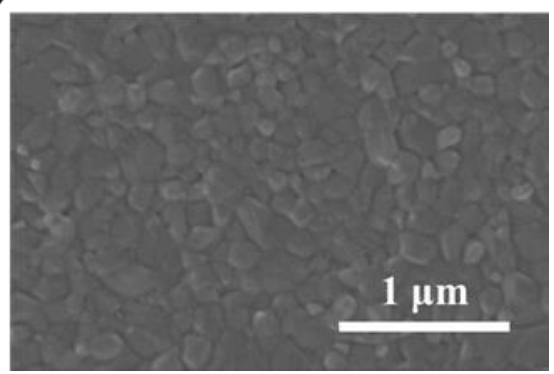

Figure S10. Surface topographic SEM images of $\mathrm{CH}_{3} \mathrm{NH}_{3} \mathrm{PbI}_{3}$ perovskite films treated without and with 0.15IPA:CB hybrid solvent.

\section{References}

(1) Zhang, S.; Zhao, L.; Yue, X.; Li, B.; Zhang, J. Density, Viscosity, Surface Tension and Spectroscopic Studies for The Liquid Mixture of Tetraethylene Glycol + N, NDimethylformamide at Six Temperatures. J. Mol. Liq. 2018, 264, 451-457.

(2) Liu, Q.; Chen, X.; Hu, W.; Zhang, M.; Ding, L.; Wang, M.; Qiao, Q.; Yang, S. Beyond Metal Oxides: Introducing Low-Temperature Solution-Processed Ultrathin Layered Double Hydroxide Nanosheets into Polymer Solar Cells Toward Improved Electron Transport. Sol. RRL 2019, 3, 1800299.

(3) Zhou, W.; Li, D.; Xiao, Z.; Wen, Z.; Zhang, M.; Hu, W.; Wu, X.; Wang, M.; Zhang, W. H.; Lu, Y.; Yang, S; Yang, S. Zwitterion Coordination Induced Highly Orientational Order of $\mathrm{CH}_{3} \mathrm{NH}_{3} \mathrm{PbI}_{3}$ Perovskite Film Delivers a High Open Circuit Voltage Exceeding 1.2 V. Adv. Funct. Mater. 2019, 29, 1901026.

(4) Wang, N.; Zhao, K.; Ding, T.; Liu, W.; Ahmed, A. S.; Wang, Z.; Tian, M.; Sun, X. W.; Zhang, Q. Improving Interfacial Charge Recombination in Planar Heterojunction Perovskite Photovoltaics with Small Molecule as Electron Transport Layer. Adv. Energy Mater. 2017, 7, 1700522.

(5) Chen, W.; Liu, F.-Z.; Feng, X.-Y.; Djurišić, A. B.; Chan, W. K.; He, Z.-B. Cesium Doped $\mathrm{NiO}_{\mathrm{x}}$ as an Efficient Hole Extraction Layer for Inverted Planar Perovskite Solar Cells. Adv. Energy Mater. 2017, 7, 1700722.

(6) Yang, J.; Liu, C.; Cai, C.; Hu, X.; Huang, Z.; Duan, X.; Meng, X.; Yuan, Z.; Tan, L.; Chen, Y. High-Performance Perovskite Solar Cells with Excellent Humidity and ThermoStability via Fluorinated Perylenediimide. Adv. Energy Mater. 2019, 9, 1900198. 